\title{
Scale-up of Circulating Fluidized Bed Coal Combustors
}

\section{Technical Progress Report}

Twelfth and Last Quarter (June 1, 1991 - August 31, 1991)

by $\mathrm{DOE} / \mathrm{PC} / 88929--\mathrm{T} 10$

Michel Yves LOUGE

Cornell University

DE92 002127

Sibley School of Mechanical \& Aerospace Engineering

Upson Hall

Ithaca, NY 14853

Work Performed under the Grant No. DE-FG22-88PC88929

For the

U.S. Department of Energy

Pittsburgh Energy Technology Center

PO Box 10940

Pittsburgh, PA 15236

US/DOE patent clearance is not required prior to the publication of this document.

\section{Table of contents}

1. Introduction and summary of accomplishments

2. Testing the heat transfer probe

3. Next research and conclusions

LITERATURE REFERENCES

Appendix: Chang H. \& Louge M.: "Hydrodynamic scale-up of circulating fluidized beds", Powder Tech. (1991), under review.

\section{DISCLAIMER}

This report was prepared as an account of work sponsored by an agency of the United States Government. Neither the United States Government nor any agency thereof, nor any of their employees, makes any warranty, express or implied, or assumes any legal liability or responsibility for the accuracy, completeness, or usefulness of any information, apparatus, product, or process disclosed, or represents that its use would not infringe privately owned rights. Reference herein to any specific commercial product, process, or service by trade name, trademark, manufacturer, or otherwise does not necessarily constitute or imply its endorsement, recommendation, or favoring by the United States Government or any agency thereof. The views and opinions of authors expressed herein do not necessarily state or reflect those of the United States Governmenti or any agency thereut. 


\section{Introduction and summary of accomplishments}

Circulating fluidization is a promising technology for designing efficient coal combustors with high solid feed rates. Unfortunately, limited understanding of circulating fluidized beds (CFB) renders design extrapolations from pilot reactors to full-scale plants both empirical and expensive. In particular, the behavior of large-scale units is unclear.

This experimental project has been aimed at quantifying the effects of scale-up upon the hydrodynamics of CFB coal combustors. To this end, we have constructed a cold CFB facility with the ability to recirculate, -rather than discard-, fluidization gas mixtures of adjustable density and viscosity. Hydrodynamic analogy between the cold bed and a coal combustor is achieved by matching all relevant dimensionless parameters (Glicksman, 1984; Louge, 1987). Several choices of gas composition and particle properties make the cold flow analogous to that in combustors of diameters in the range 0.3 to $1 \mathrm{~m}$. Therefore, for the first time, scale-up effects are quantified directly using a single cold flow facility.

During the facility's commissioning stage, we performed the first quantitative, timedependent measurements of voidage in the wall region of the bed. The data established the presence of a dense curtain of solids falling near the wall. (Louge, Lischer \& Chang, 1990). In other experiments, we showed that, if unchecked, electrostatics has significant effects on the flow. In this regard, we have found a powerful anti-static additive that virtually eliminates the problem.

The scale-up experiments were completed in earlier reporting periods. By comparing data obtained in these experiments, we have verified the hydrodynamic analogy predicted by the dimensional analysis, determined scale-up rules for static pressure and its fluctuations, and investigated choking in risers of increasing sizes. In addition, by fluidizing two glass powders of identical characteristics but largely different surface friction coefficients, we have discovered, to our surprise, that particle friction affects the flow. The resulting publication is appended to the present report (Chang \& Louge, 1991).

Because particles undergo frequent collisions in the CFB, we have also devoted some effort to modeling their interaction in gas-solid flows using elements of rapid granular theories. Because detailed measurements of velocity and velocity fluctuations are not yet available in dense flows, we have first considered dilute, turbulent flows of relatively massive particles, for which Tsuji, et al. (1984) had published detailed data. A numerical solution of the resulting governing equations has provided velocity and turbulent energy profiles in good agreement with the measurements of Tsuji et al. (1984), and it has shown that particle collisions can play an important role even under dilute conditions (Louge, 
Mastorakos \& Jenkins, 1991). Encouraged by these results, we have also modeled heat transfer from a suspension of massive particles of low Biot number transported in a vertical pipe (Louge, Mohd. Yusof, \& Jenkins 1991).

During the present reporting period, our students have focused attention on completing some of their thesis requirements. In addition, they have begun testing and modifying a miniature probe that measures simultaneously the heat transfer rate and the solid volume fraction at the wall of a CFB.

\section{Testing the heat transfer probe}

The principle of this non-invasive probe can be found in our second quarterly report. Heat flux is recorded by a small platinum coil located near the surface of one of our 'wall' capacitance probes. The coil is maintained at constant temperature using a control circuit. The power supplied to the coil is a measure of the heat flux supplied to the bed. To allow the capacitance probe to record voidage, the surface of the platinum coil must be maintained at the ground voltage. In the original design, this end was achieved using a thin metal cap covering the coil. The test of this original configuration was carried out in the present reporting period.

In the test, the probe is inserted flush with the wall of a two-dimensional fluidized bed of $70 \mu \mathrm{m}$ glass beads. Unfortunately, this first test showed that the thin metal cap dissipates a greater amount of energy by conduction through the body of the probe than the convective heat flux supplied to the fluidized bed. To avoid these excessive conduction losses, we have replaced the cap with a thin layer of conductive paint above annther thin layer of epoxy. The epoxy isolates the coil from the paint and provides sufficient structural rigidity to help the coil withstand repeated particle collisions. The paint is maintained at the ground voltage for the capacitance measurement. Tests of the new configuration are now underway at Cornell.

\section{Next research and conclusions}

Tests of the heat transfer probe will continue in the next reporting period. For this we have obtained a six-month no-cost extension of this project. In addition, we will prepare the final report for this project. After this work, we plan a research program integrating theory, computer simulation, and experiments that will focus on the dynamics of the wall layer and its effects on tube erosion and heat transfer. Experiments will be carried out in an existing circulating bed whose flow is analogous to that of a coal combustor. There, sensors recently developed at Cornell will measure particle volume fraction, collision frequency and heat transfer at the wall. 


\section{REFERENCES}

- Chang, H. \& Louge, M.: "Hydrodynamic scale-up of circulating fluidized beds", Powder Tech. (1991), under review.

- Glicksman, L.: Chem. Eng. Sci. 39, 1373 (1984).

- M. Louge: "Scale-up of Circulating Fluidized Bed Coal Combustors", Tech. Prog. Rep., First to Eleventh Quarters (Dec. 1, 1988 - May 31, 1991), Grant DE-FG22-88PC88929.

- M. Louge: "Circulating Fluidization Research at Cornell: A Study of Hydrodynamic Scale-up Effects", Prnc. 9th Int. Conf. on Fluid. Bed Comb., ASME (1987) p. 1193-97.

- M. Louge, D.J. Lischer \& H. Chang: "Measurements of Voidage near the Wall of a Circulating Fluidized Bed Riser", Powder Tech. 62, 267-74 (1990).

- M. Louge, E. Mastorakos \& J.T. Jenkins: "The Role of Particle Collisions in Pneumatic Transport" J. of Fluid Mech., accepted for publication, February 1991.

- M. Louge, J. Mohd. Yusof \& J.T. Jenkins: "Heat Transfer in the Pneumatic Transport of Massive Particles", Int. J. Heat and Mass Transfer (1991), under review.

- Tsuji, Y., Morikawa, Y. \& Shiomi, H. "LDV measurements of an air-solid two-phase flow in a vertical pipe", J. Fluid Mech. 139, 417-34 (1984). 

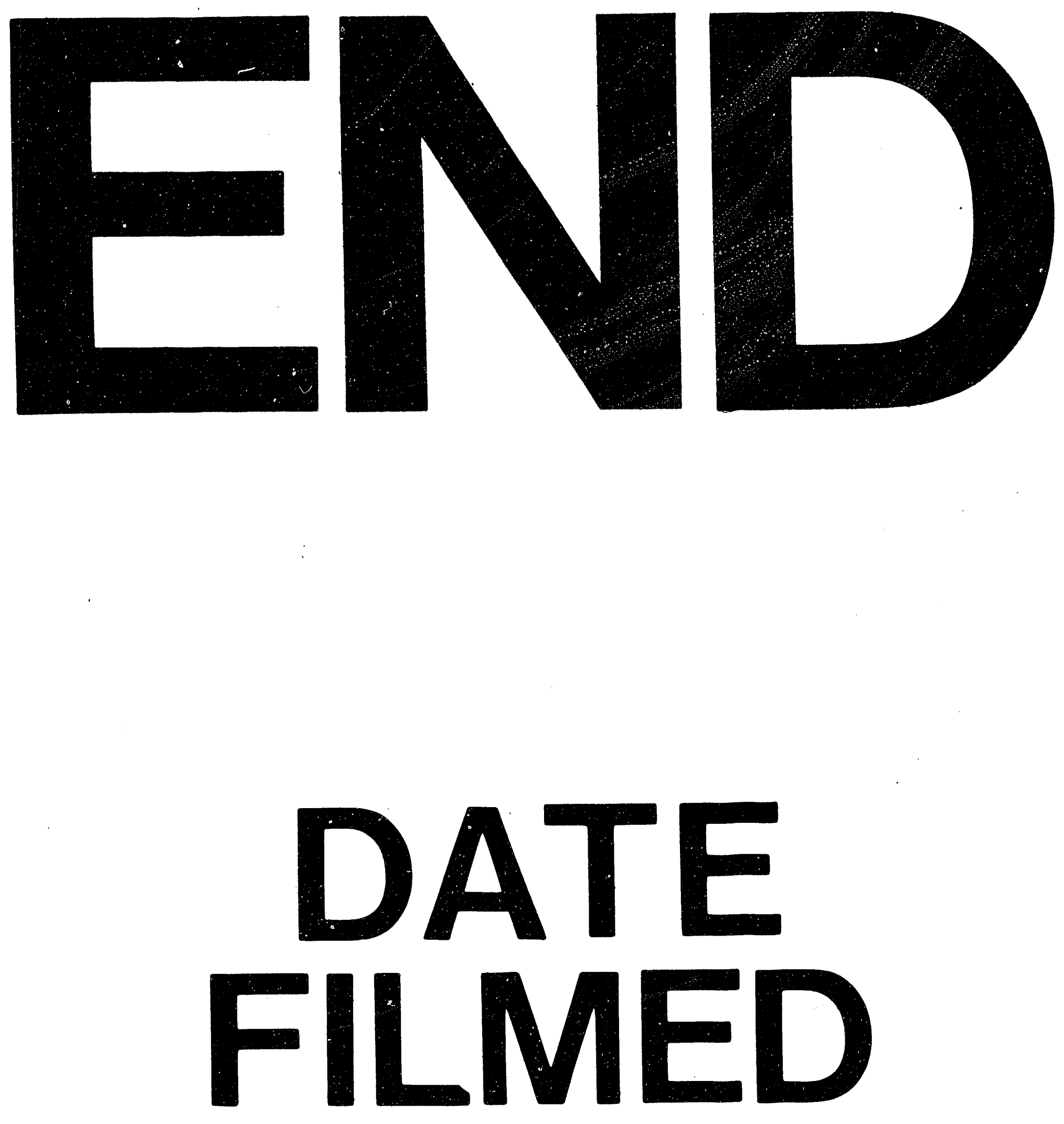

1

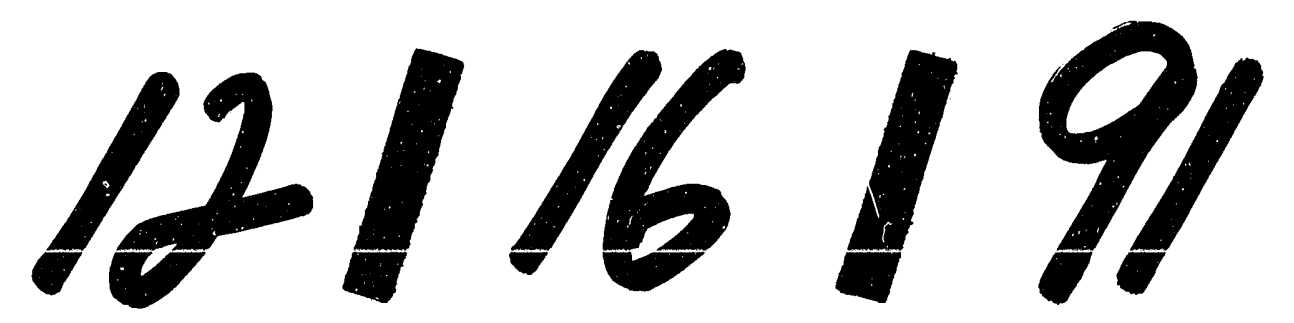


I 